\title{
DISEÑO DE ESCENARIOS PARA UNA POLÍTICA FORESTAL EN LA COMUNITAT VALENCIANA
}

\author{
Brenda García Domínguez ${ }^{\text {**, }}$, María Gonzalez Sanchis ${ }^{\mathrm{b}}$ y Dionisio Ortiz Miranda ${ }^{\mathrm{c}}$ \\ ${ }^{a}$ Escuela Técnica Superior de Ingeniería Agronómica y del Medio Natural, Universitat Politècnica de \\ València (bregardo@alumni.upv.es) \\ ${ }^{b}$ Instituto Universitario de Ingeniería del Agua y del Medio Ambiente, Universitat Politècnica de València \\ (macgonsa@gmail.com) \\ c Departamento de Economía y Ciencias Sociales, Universitat Politècnica de València (dortiz@upv.es)
}

\section{Resumen}

Los análisis de prospectiva basados en escenarios se han convertido en los últimos años en una importante herramienta para la planificación y la formulación de políticas públicas en numerosos ámbitos. El presente trabajo recoge un análisis participativo prospectivo de escenarios orientado a contribuir a la toma de decisión en el ámbito de las políticas forestales de la Comunitat Valenciana.

El trabajo se ha realizado a lo largo de las siguientes etapas: (1) recopilación a partir de una revisión bibliográfica de un total de 18 factores de cambio que pueden tener incidencia en los montes valencianos; (2) valoración de estos indicadores por parte de un conjunto de expertos a partir de tres criterios: relevancia, grado de incertidumbre y capacidad de influencia desde las políticas autonómicas; (3) tratamiento estadístico descriptivo de los resultados con el fin de entender las valoraciones recibidas por dichos factores, así como el grado de consenso entre los expertos.

En base a estos tres criterios, los dos factores que aparecen señalados como más relevantes son Coordinación de los departamentos administrativos sectoriales y Nivel de gasto público. A partir de estos dos factores se puede configurar un marco de escenarios que podría servir de base para la implementación de un proceso participativo para el desarrollo de los escenarios.

Palabras clave: Análisis prospectivo, escenarios, política forestal, monte mediterráneo, Comunitat Valenciana

\section{Introducción}

La Comisión Europea define la prospectiva como un proceso que combina tres elementos fundamentales: como enfoque (una mirada a largo plazo), como planificación (incluyendo la toma de decisión política y el establecimiento de prioridades) y la participación (implicando a los actores y las diversas fuentes de conocimiento) (Popper, 2009). Así, tal como plantea McEldowney (2017: 2) "los estudios de prospectiva implican la identificación de imágenes alternativas del futuro y la elección de acciones basadas en esas imágenes. No se trata de predecir el futuro, sino de explorar un abanico de posibles futuros apoyados por el análisis de las tendencias científicas y tecnológicas". Esta visión prospectiva es esencial para la planificación de las acciones necesarias para afrontar los retos socioeconómicos y climáticos a los que ha de enfrentarse el monte mediterráneo.

El objetivo de este trabajo es doble. En primer lugar, pretende identificar y carcaterizar, a partir de consultas a un grupo de expertos, los factores de cambio que incidirán en mayor medida en el futuro del monte valenciano, analizando en cuáles de ellos tiene capacidad de incidencia la política autonómica. En segundo lugar, persigue construir unos escenarios sobre los que podrían desarrollarse una serie de narrativas que podrían servir de apoyo a los tomadores de decisiones a desarrollar planes y políticas regionales, así como a los diversos actores a planificar sus estrategias de adaptación.

\section{Marco conceptual}

El análisis prospectivo basado en el diseño de escenarios de futuro se ha convertido en un potente instrumento para la formulación de las políticas públicas en numerosos ámbitos. Destaca en este sentido la planificación estratégica de escenarios, definida por Otero-Rozas et al. (2015) como un proceso en el que los actores, con frecuencia guiados por investigadores, se implican en un proceso colaborativo y desarrollan un papel de liderazgo a lo largo de las distintas fases del desarrollo de escenarios que investigarán futuros alternativos. En este contexto, los escenarios pueden ser definidos como una descripción de cómo el futuro podría 'desplegarse' de acuerdo a un conjunto explícito de asunciones, coherente e internamente consistente sobre las relaciones entre una serie de factores de cambio (Forward Thinking Platform, 2014).

Los factores de cambio (drivers) han sido definidos de numerosas maneras. En este trabajo adoptamos una definición que adapta la que realizan Béné et al. (2019) en relación a los sistemas alimentarios. Así, entendemos como factores de cambio aquellos procesos endógenos o exógenos que, ya sea de forma deliberada o no intencionada, afectan o influyen el estado del monte mediterráneo en la Comunitat 
Valencian a lo largo de un período de tiempo suficientemente largo, de manera que su impacto altera de forma duradera las actividades y los bienes y servicios de dicho ecosistema.

\section{Metodología}

A continuación se detallan las fases seguidas en el diseño metodológico. En primer lugar, se realizó una revisión bibliográfica de estudios prospectivos sobre los recursos forestales en el ámbito europeo y europeo. De igual modo, se complementó con literatura del ámbito de los sistemas alimentarios, por encontrar en ella factores de relevancia. No se incluyó el cambio climático como un factor de cambio en sí mismo, siguiento los planteamientos de Béné et al. (2019). A partir de esta revisión se selecionaron 18 factores de cambio.

En segundo lugar, este listado (con sus correspondientes definiciones) se remitió a un conjunto de expertos para que los valorasen. En el estudio participaron 15 expertos, en su mayoría ingenieros/as de montes, pertenecientes a diversos ámbitos: universidad, administraciones (autonómica, provincial y local) y asociaciones de propietarios forestales públicos y privados. Estos expertos valoraron (de 0 a 10) los factores de cambio que se les propusieron en base a tres criterios:

1. Grado de relevancia que tiene este factor para el futuro de los montes valencianos.

2. Grado de incertidumbre asociado a cada factor.

3. Capacidad de influencia desde la política autonómica para influir en la evolución de dicho factor. Los resultados de estas valoraciones son analizados en relación a las medianas de las respuestas y el grado de covergencia entre los expertos. Finalmente, se seleccionan los dos factores de mayor importancia para el diseño de un marco de escenarios.

\section{Resultados}

La búsqueda bibliográfica sobre los factores de cambio permitió identificar algunos documentos clave relacionados con el sector forestal, en especial Wolfslehner et al. (2020) y Mora et al. (2014). Esta revisión se complementó con la realizada por Béné et al. (2019) para el sistema alimentario por incorporar factores que los autores de esta comunicación entendieron relevantes para el estudio. Finalmente, se elaboraron los factores de cambio que aparecen en el Cuadro 1 para su valoración por parte de los expertos.

Cuadro 1. Factores de cambio utilizados

\begin{tabular}{|l|}
\hline \multicolumn{1}{|c|}{ Factor* } \\
\hline 1. Evolución demográfica en las zonas rurales \\
\hline 2. Importancia del valor que la sociedad concede de los servicios forestales no materiales \\
\hline 3. Demanda de usos turísticos en el medio rural \\
\hline 4. Grado de implantación de un modelo de bioeconomía \\
\hline 5. Liberalización/proteccionismo del comercio internacional \\
\hline 6. Nivel de digitalización \\
\hline 7. Desarrollo de las innovaciones tecnológicas \\
\hline 8. Desarrollo de innovaciones sociales \\
\hline 9. Aumento/disminución de la normativa de conservación de ENP \\
\hline 10. Aumento/disminución del peso de la Unión Europea en la política forestal \\
\hline 11. Centralización/descentralización de la acción política en España \\
\hline 12. Aumento/disminución de la incidencia de la participación pública en las políticas \\
\hline 13. Aumento/disminución del poder de las corporaciones en influir en las políticas \\
\hline 14. Coordinación de los departamentos administrativos sectoriales \\
\hline 15. Nivel de gasto público \\
\hline 16. Rentabilidad de la actividad agraria y ganadera \\
\hline 17. Demanda de productos forestales no madereros \\
\hline 18. Nivel de la renta per cápita regional \\
* La información enviada a los expertos añadía una explicación más detallada del significado de estos \\
factores de cambio. \\
Fuente: Elaboración propia \\
\hline
\end{tabular}

Fuente: Elaboración propia

Los siguientes Gráficos muestran los resultados de las valoraciones realizadas por los expertos para cada uno de los tres criterios. 
Gráfico 1. Diagramas de caja de las respuestas de los expertos para cada factor
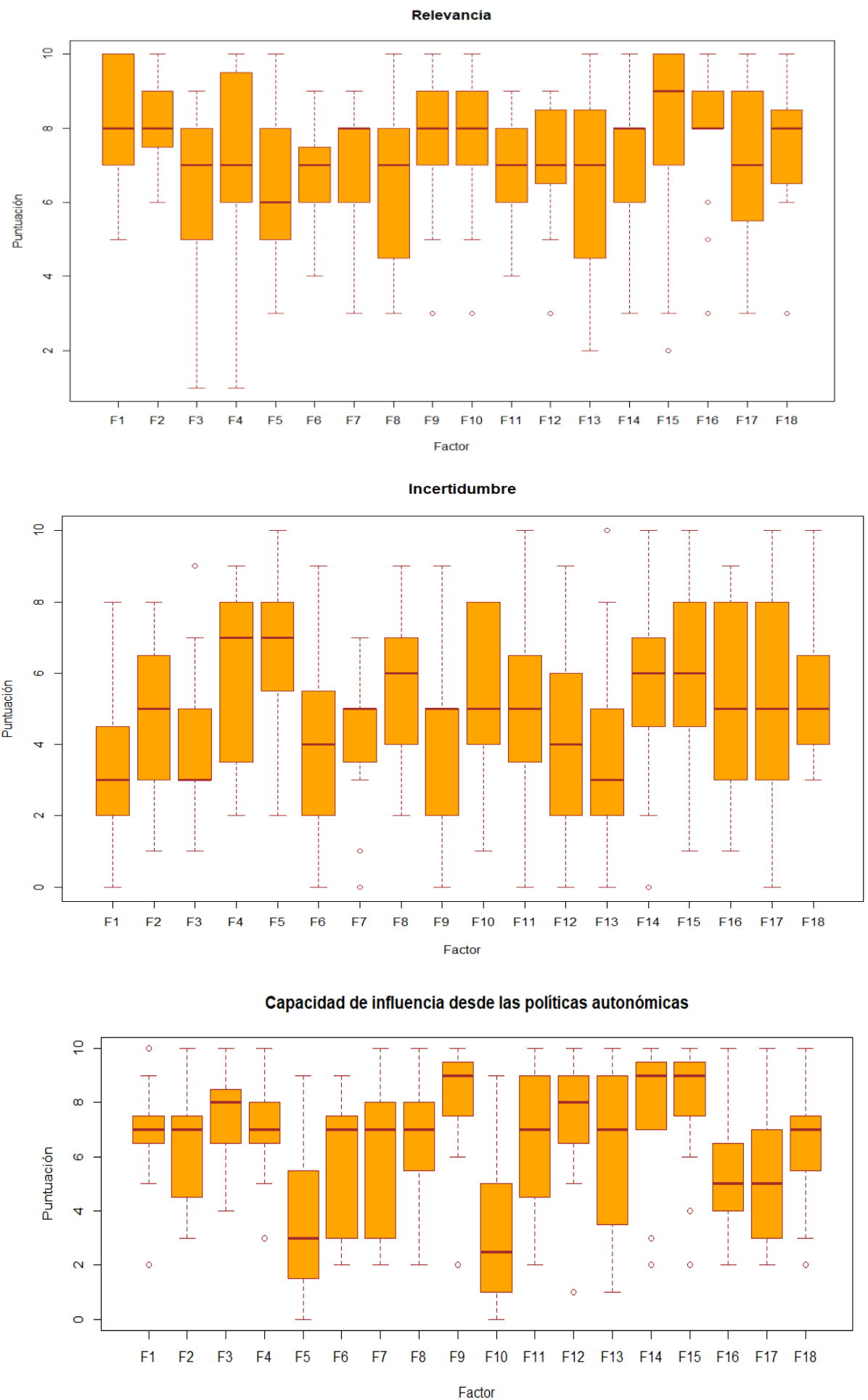

Fuente: Elaboración propia

En los diagramas pueden identificarse los factores que presentan unos mayores valores de sus medianas para cada uno de los tres criterios: Relevancia (F9. Nivel de gasto público), Incertidumbre (F4 Grado de implantación de un modelo de bioeconomía y F5 Liberalización/proteccionismo del comercio internacional) y capacidad de influencia desde las políticas autonómicas (F14 Coordinación de los departamentos administrativos sectoriales y F15 Nivel de gasto público).

La combinación de estos tres criterios es importante para el diseño de escenarios orientados a la formulación de las políticas públicas a nivel autonómico, ya que (i) se toma en consideración la relevancia sobre su 
impacto en el monte mediterráneo, (ii) los escenarios deben priorizar en su diseño aquellos elementos que mayor grado de incertidumbre presentan, cubriendo así un mayor espectro de futuros posibles, y (iii) se centra en aquellos aspectos sobre las que las competencias autonómicas tienen alcance. Son diversas las formas en las que se podrían haber combinado estos criterios, como por ejemplo a través de una agregación ponderada por los pesos asignados por el mismo grupo de expertos. Sin embargo, en nuestro caso se realiza una sencilla suma aritmética de las medianas de los factores para seleccionar los dos de mayor puntuación y construir con ellos un marco de escenarios que pudiese ser pertinente para encuadrar la planificación prospectiva. Estos dos factores son $\mathrm{F} 14$ Coordinación de los departamentos administrativos sectoriales y F15 Nivel de gasto público. A partir de estos dos factores se puede configurar un marco de escenarios que podría servir de base para la implementación de un proceso participativo para el desarrollo de los escenarios. El gráfico 2 ilustra este marco, donde se han añadido unos títulos orientativos de cada escenario.

Gráfico 2. Un marco de escenario para el desarrollo de las narrativas

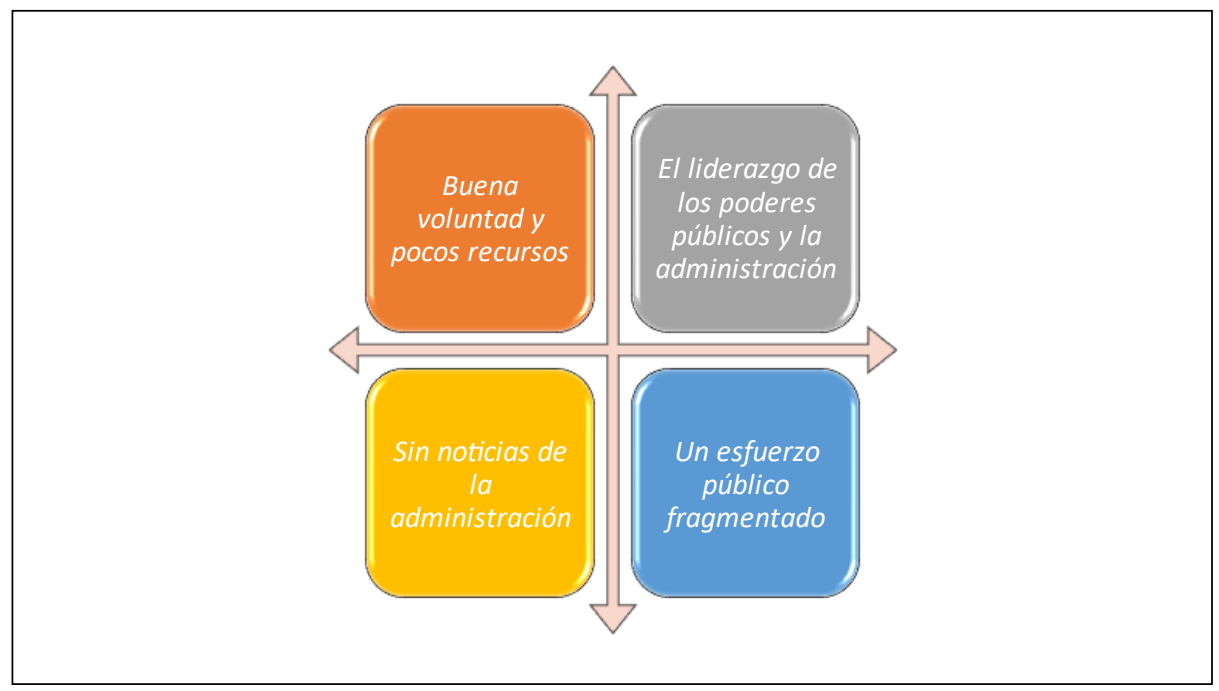

Fuente: Elaboración propia

\section{Conclusión}

El análisis participativo de escenarios ha permitido configurar un marco de escenarios que enfatiza dos factores de cambio que los expertos consultados consideran, por diferentes motivos, claves para el futuro del monte valenciano. A partir de este esquema se podrían iniciar un proceso participativo más amplio que implique a los numerosos actores de cuyas decisiones depende este futuro, de manera que se pudiese convertir también en un mecanismo de establecimiento de acuerdos y una visión compartida sobre las mejores vías para preservar los valores de los ecosistemas forestales valencianos ante un futuro lleno de incertidumbres.

\section{Referencias}

Béné, C., et al. (2019). "Understanding food systems drivers: A critical review of the literature". Global Food Security. 23: 149-159.

Forward Thinking Platform (2014). A Glossary of Terms commonly used in Futures Studies.

McEldowney, J. (2017). Foresight - Contribution to the debate on the future of EU agricultural policy. European Parliament Research Service, September 2017.

Mora, O., Banos, V., Regolini, M., Carnus, J.M. (2014). "Using scenarios for forest adaptation to climate change: a foresight study of the Landes de Gascogne Forest 2050". Ann. forest science, 71(3): 313-324.

Oteros-Rozas, E., et al. (2015). "Participatory scenario planning in place-based social-ecological research: insights and experiences from 23 case studies”. Ecology and Society. 20(4): 32.

Popper, R. (2009). Mapping Foresight: Revealing how Europe and other world regions navigate into the future, EFMN, Luxembourg.

Wolfslehner, B. et al. (2020). European forest governance post-2020. From Science to Policy, 10. European Forest Institute. https://doi.org/10.36333/fs10 